\title{
Artemether administered together with haemin damages schistosomes in vitro
}

\author{
Xiao Shuhua ${ }^{1,2}$, Jacques Chollet, Jürg Utzinger ${ }^{2}$, Hugues Matile ${ }^{2,3}$, Mei Jinyan ${ }^{1}$ and Marcel Tanner ${ }^{2 \star}$ \\ ${ }^{1}$ Institute of Parasitic Diseases, Chinese Academy of Preventive Medicine, Shanghai 200025, China; ${ }^{2}$ Swiss Tropical Institute, \\ PO Box, CH-4002 Basel, Switzerland; ${ }^{3}$ F. Hoffmann-La Roche Ltd, CH-4070 Basel, Switzerland
}

\begin{abstract}
We conducted experiments in vitro to assess the effect of artemether in combination with haemin on adult $S c h i s t o s o m a j a p o n i c u m, S$. mansoni and $S$. haematobium. When schistosomes were maintained in a medium containing artemether at concentrations of $20 \mu \mathrm{g} / \mathrm{mL}$ or less for $72 \mathrm{~h}$, no apparent effect on the schistosomes was seen. When the medium contained 50 or $100 \mu \mathrm{g} / \mathrm{mL}$ haemin as well as artemether, the schistosomes showed decreased motor activity $2-24 \mathrm{~h}$ after exposure, which was followed by the staining of the whole worm body a reddish-yellow colour, dilatation of the intestine, and extensive vesiculation of the tegument. Some of the schistosomes died $24 \mathrm{~h}$ after exposure, and almost all died within $48-72 \mathrm{~h}$. When schistosomes were exposed to the same concentrations of hacmin alone, they were stained a light yellow colour but there was no apparent effect on their survival. Our findings suggest that artemether interacts with haemin to exert a toxic effect on the worms, which might be of importance in the further elucidation of the mechanism of action of artemether on schistosomes.
\end{abstract}

Keywords: schistosomiasis, Schistosoma japonicum, Schistosoma mansoni, Schistosoma haematobium, artemether, haemin

\section{Introduction}

Artemether, a derivative of artemisinin, is used effectively in the treatment of severe malaria and multidrugresistant falciparum malaria (MCINTOSH \& OLLIARO, 1999). Summarizing the data dealing with the interaction of artemisinin with haemin, heme and free iron, a two-step mechanism of action against malaria parasites has been proposed (KAMCHONwONGPAISAN \& MESHNICK, 1996; MESHNICK et al., 1996; MESHNICK, 1998; DHINGRA et al., 2000). Artemisinin is activated by intraparasitic iron, which catalyses the cleavage of the endoperoxide bridge and the generation of free radicals. This is followed by alkylation and the formation of covalent bonds betwcen artemisinin-derived frec radicals and parasite protein(s).

During the early 1980 s, artemether was also found to be active against Schistosoma japonictum (see LE et al., 1982). Detailed laboratory studies showed that the juvenile stages of the parasite were more susceptible than the adult worms (XIAO et al., 1995, 1998a). Consequently, the use of artemether for prophylaxis against $S$. japonicum was developed through experimental studies and a series of clinical trials in humans (for a review, see XIAO et al., 2000a). Laboratory studies also showed that artemether has a prophylactic effect against $S$. mansoni (see XIAO \& CATTO, 1989; XIAO et al., 2000b) and $S$, haematobium (see XIAO et al, 2000c). Recently, the laboratory findings with $S$. mansoni have been confirmed in a randomized controlled trial in humans (UTZINGER et al., 2000), and a similar trial is currently under way with $S$. haematobium.

In our earlier work, artemether was found to exert various effects on schistosomes in vivo. Movement of worms to the liver (hepatic shift) started $8 \mathrm{~h}$ after drug administration and reached a peak after $72 \mathrm{~h}$ (XIAO \& CATTO, 1989). Artemether had extensive effects on carbohydrate, nucleic acid and protein metabolism of the schistosomes, and enzymes related to the corresponding biochemical process were markedly inhibited after 48-72 h (YOU et al., 1994; XIAO et al., 1997, $1998 \mathrm{~b}, 1998 \mathrm{c}, 1999$; ZHAI et al., 1999). On the other hand, artemether at concentrations less than $100 \mu \mathrm{g} / \mathrm{mL}$. had no apparent action on schistosomes in vitro (XIAO \& CATTO, 1989). It was therefore interesting to investigate the mechanism of the observed in vivo effects.

Since blood cells are taken up by schistosomes about 2 weeks after entry into the mammalian host (CLEGG, 1965 ), and pigment resulting from the metabolism of haemoglobin is formed in their intestines (KLOETZEL \& LEWERT, 1966), it is possible that an interaction between

Author for correspondence: phone +41612848283 , fax +41 612717951 , e-mail marcel tanner(o)unibas.ch artemether and iron-containing metabolites of haemoglobin may occur. By analogy with the assumed mechanism of action of artemisinin antimalarial compounds, the generation of free radicals (BUTLER et al, 1998) could also play a role in killing the schistosomes. The present paper represents a first step to investigate in vitro the possible effect of artemether in combination with haemin on schistosomes, which may be of relevance in understanding the possible mechanism of its action.

\section{Materials and Methods}

Parasites

S. japonicum cercariae (Anhui isolate), released from infected Oncomelania hupensis snails, were provided by the Institute of Parasitic Diseases, Chinese Academy of Preventive Medicine (Shanghai, China). S. mansoni cercariae (Liberia isolate), released from infected Biomphalaria glabrata snails, were provided by the Swiss Tropical Institute (Basel, Switzerland). S. haematobium cercariae (Cote d'Ivoire isolate) were obtained after the first experimental passage through the sympatric snail intermediate host Bulinus truncatus. The snails were kept and infected in the laboratory of UFR Bioscience, University of Cocody (Abidjan, Côte d'Ivoire) and then transferred to the laboratory of the Swiss Tropical Institute for release and collection of cercariae.

\section{Host animals}

Male and female Kunming strain mice, weighing 22$24 \mathrm{~g}$, provided by Shanghai Animal Centre, Chinese Academy of Sciences (Shanghai, China), were used for infection with $S$. japonictum. Female MORO strain mice (specific pathogen-free), weighing $18-22 \mathrm{~g}$, obtained from the Biotechnology and Animal Breeding Division of RCC Ltd (Füllinsdorf, Switzerland) were used for infection with $S$. mansoni. Four male hamsters, weighing $6080 \mathrm{~g}$, of the Lake LVG(SYR)BR strain, were also obtained from the Biotechnology and Animal Breeding Division of RCC Ltd and used for infection with $S$. haematobium. All animals were maintained on commercial rodent food.

\section{Infection and collection of schistosomes}

The Kunming strain mice were infected with 80-100 S. japonictm cercariae via the shaved abdominal skin. The MORO mice were infected subcutaneously with 80-200 S. mansoni cercariae. Hamsters were infected subcutaneously with $400 \mathrm{~S}$. haematobium cercariae.

Mice infected with $S$, japonicum for 32-38 d and mice infected with $S$. mansoni for $42-56$ d were killed by bleeding. The schistosomes were collected by perfusion (YoL.IES et al., 1947) with ice-cold Hanks's balanced salt solution (HBSS) from mesenteric veins and livers, rinsed 
3 times with HBSS containing $300 \mathrm{iu} / \mathrm{mL}$ penicillin sodium and $300 \mathrm{iu} / \mathrm{mL}$ streptomycin and kept in an ice bath. Hamsters infected with $S$. haematobium were also killed by bleeding, $77 \mathrm{~d}$ after infection. The intact intestines of the hamsters were removed and placed in a Petri dish. Schistosomes were removed from the mesenteric veins under a stereoscopic microscope with small forceps, following a procedure described in detail elsewhere (XIAO et al., 2000b).

\section{Drugs and chemicals}

Artemether was the product of Kunming Pharmaceutical Corporation (Kunming, China; lot no. 970801). A stock solution of artemether was prepared by dissolving $5 \mathrm{mg}$ of the drug in $3 \mathrm{~mL}$ polyethylene glycol (PEG 400 ) and then adding $2 \mathrm{mLHBSS}$ to give a stock solution with $1 \mathrm{mg}$ artemether per millilitre. This was diluted with HBSS for use. Haemin was obtained from Fluka (Buchs, Switzerland). Fresh haemin solution was prepared by dissolving $5 \mathrm{mg}$ of haemin in $1 \mathrm{~mL} 0.1 \mathrm{M} \mathrm{NaOH}$ and adding $3.95 \mathrm{~mL}$ of HBSS followed by $0.05 \mathrm{~mL}$ of $1 \mathrm{M}$ $\mathrm{HCl}$ to adjust the $\mathrm{pH}$ to $7 \cdot 2-7 \cdot 4$.

\section{Schistosome incubation in vitro}

The incubation methods used for $S$. japonicum, $S$. mansoni and $S$, haematobium were identical. HBSS supplemented with $10 \%$ heat-inactivated calf serum, $300 \mathrm{iu} / \mathrm{mL}$ penicillin sodium, $300 \mathrm{iu} / \mathrm{mL}$ streptomycin and $0.25 \mathrm{mg} / \mathrm{L}$ amphotericin $B$ was used to maintain the schistosomes in vitro. 1.78-2.00 mL of the medium were added to each of the 24 wells of a Falcon plate, then 2 pairs of worms were placed in each well. The plate was incubated at $37^{\circ} \mathrm{C}$ in $95 \%$ air $+5 \% \mathrm{CO}_{2}$ for $20-30 \mathrm{~min}$ before addition of artemether at various concentrations $(0.5,2.5,5,10$ and $20 \mu \mathrm{g} / \mathrm{mL})$. After the schistosomes had been exposed to artemether for $2 \mathrm{~h}, 50$ or $100 \mu \mathrm{g} / \mathrm{mL}$ haemin were addcd. The final volume in each well was $2.0 \mathrm{~mL}$. Control wells contained worms and medium only, medium plus the same concentrations of either artemether or haemin, or $0.6 \div 1.2 \%$ PEG 400 alone (depending on the artemether concentration: for $0.5-$ $10 \mu \mathrm{g} / \mathrm{mL}$ artemether $0.6 \%$ PEG 400 , for $20 \mu \mathrm{g} / \mathrm{mL}$ artemether $1.2 \%$ PEG); they were maintained for the same time as experimental worms in a final volume of $2.0 \mathrm{~mL}$.

After addition of the above-mentioned substances, the plates were incubated continuously for $72 \mathrm{~h}$. The different combinations of artemether plus haemin and con- centrations of artemether or haemin alone were tested 2 or 3 times with adult worms of all 3 schistosome species.

\section{Assessment of drug effects}

After $2,4,6,8,18,24,48$ and $72 \mathrm{~h}$, motor activity, tegumental alterations and parasite survival were assessed by examination under an inverted microscope and recorded. Parasite death was defined as no motor activity during 2 min observation plus severe and extensive tegumental alteration (i.e., more than $50 \%$ of the tegumental surface showing severe and extensive alterations, including vesiculation and collapse of large vesicles).

\section{Results}

The results are summarized in Tables $1-3$.

Effect of polyethylene glycol, haemin or artemether alone

After incubation in medium containing $0.6 \%$ or $1.2 \%$ polyethylene glycol or haemin at 50 or $100 \mu \mathrm{g} / \mathrm{mL}$, all individuals of $S$. japonicum, S. mansoni and $S$. haematobium showed a normal appearance with no tegumental damage. A slight decrease in motor activity was seen in a few worms after $72 \mathrm{~h}$ exposure; however, all worms were still alive at the end of the experiments.

No apparent alteration either in motor activity or in the tegument was seen when the 3 different schistosome species were exposed to various concentrations of artemether alone, and all schistosomes survived $72 \mathrm{~h}$ of incubation.

\section{Effect of artemether together with haemin}

When adult $S$. japonicum worms which had been maintained in medium containing $0.5 \mu \mathrm{g} / \mathrm{mL}$ artemether for $2 \mathrm{~h}$ were exposed to haemin at 50 or $100 \mu \mathrm{g} / \mathrm{mL}$, the motor activity of the worms decreased after about $24 \mathrm{~h}$ incubation and stiffness of the worm body was observed. Motor activity decreased about $6-8 \mathrm{~h}$ earlier if the worms were exposed to the same concentrations of haemin but higher concentrations of artemether $(2.5,5$ or $10 \mu \mathrm{g} / \mathrm{mL}$ ). When adult worms of $S$, haematobium or $S$. mansoni were exposed to 5 or $10 \mu \mathrm{g} / \mathrm{mL}$ artemether together with 50 or $100 \mu \mathrm{g} / \mathrm{mL}$ haemin, reduction in motor activity was observed earlier than with $S$. japonicum: after $2-4$ h with adult $S$. haematobium and after 4 $8 \mathrm{~h}$ with adult $S$. mansoni worms. Usually, decrease of motor activities was accompanied by a gradual decrease in intestinal movement.

Table 1. Mortality rates of adult Schistosoma japonicum after exposure in vitro to artemether or haemin, or both substances

\begin{tabular}{|c|c|c|c|c|c|c|c|c|}
\hline \multirow[b]{3}{*}{ Treatment $^{\mathrm{a}}$} & \multirow{2}{*}{\multicolumn{2}{|c|}{$\begin{array}{l}\text { No. of worms } \\
\text { initially }^{\mathrm{b}}\end{array}$}} & \multicolumn{6}{|c|}{ No. of worms dead after incubation ${ }^{b}$} \\
\hline & & & \multicolumn{2}{|c|}{$24 \mathrm{~h}$} & \multicolumn{2}{|c|}{$48 \mathrm{~h}$} & \multicolumn{2}{|c|}{$72 \mathrm{~h}$} \\
\hline & $\mathbf{m}$ & $f$ & $\mathbf{m}$ & $\mathrm{f}$ & $\mathbf{m}$ & $\mathrm{f}$ & $\mathrm{m}$ & $f^{\prime}$ \\
\hline Control (medium only) & 6 & 6 & 0 & 0 & 0 & 0 & 0 & 0 \\
\hline Polyethylene glycol $(0.6 \%)$ & 6 & 6 & 0 & 0 & 0 & 0 & 0 & 0 \\
\hline Haemin (50) & 6 & 6 & 0 & 0 & 0 & 0 & 0 & 0 \\
\hline Haemin (100) & 6 & 6 & 0 & 0 & 0 & 0 & 0 & 0 \\
\hline Artemether $(0.5)$ & 4 & 4 & 0 & 0 & 0 & 0 & 0 & 0 \\
\hline Artemether (2.5) & 4 & 4 & 0 & 0 & 0 & 0 & 0 & 0 \\
\hline Artemether (5) & 6 & 6 & 0 & 0 & 0 & 0 & 0 & 0 \\
\hline Artemether $(0.5)+$ haemin (50) & 4 & 4 & 0 & 0 & 0 & 0 & 2 & 1 \\
\hline Artemether $(0.5)+$ haemin $(100)$ & 4 & 4 & 0 & 0 & 1 & 0 & 4 & 4 \\
\hline Artemether $(2.5)+$ haemin $(50)$ & 4 & 4 & 0 & 0 & 4 & 4 & - & - \\
\hline Artemether (2.5) + haemin (100) & 4 & 4 & 0 & 0 & 4 & 4 & - & - \\
\hline Artemether (5) + haemin (50) & 6 & 6 & 0 & 0 & 4 & 4 & 6 & 6 \\
\hline Artemether (5) + haemin (100) & 6 & 6 & 2 & 2 & 6 & 6 & - & - \\
\hline Artemether (10) + haemin (50) & 4 & 4 & 0 & 0 & 4 & 0 & - & 4 \\
\hline
\end{tabular}

"Concentrations of artemether and haemin in $\mu \mathrm{g} / \mathrm{mL}$ are given in parentheses.

${ }^{\mathrm{b}} \mathrm{m}=$ Male, $\mathrm{f}=$ female. 
Table 2. Mortality rates of adult Schistosoma mansoni after exposure in vitro to artemether or haemin, or both substances

\begin{tabular}{|c|c|c|c|c|c|c|c|c|}
\hline \multirow[b]{3}{*}{ Treatment $^{a}$} & \multirow{2}{*}{\multicolumn{2}{|c|}{$\begin{array}{l}\text { No. of worms } \\
\text { initially }\end{array}$}} & \multicolumn{6}{|c|}{ No. of worms dead after incubation } \\
\hline & & & \multicolumn{2}{|c|}{$24 \mathrm{~h}$} & \multicolumn{2}{|c|}{$48 \mathrm{~h}$} & \multicolumn{2}{|c|}{$72 \mathrm{~h}$} \\
\hline & $\mathrm{m}$ & f & $\mathrm{m}$ & $\mathbf{f}$ & In & $\mathbf{f}$ & m & f \\
\hline Control (medium only) & 12 & 10 & 0 & 0 & 0 & 0 & 0 & 0 \\
\hline Polyethylene glycol $(0.6 \%)$ & 8 & 7 & 0 & 0 & 0 & 0 & 0 & 0 \\
\hline Haemin $(50)$ & 10 & 10 & 0 & 0 & 0 & 0 & 0 & 0 \\
\hline Haemin $(100)$ & 10 & 10 & 0 & 0 & 0 & 0 & 0 & 0 \\
\hline Artemether (5) & 5 & 5 & 0 & 0 & 0 & 0 & 0 & 0 \\
\hline Artemether $(10)$ & 7 & 6 & 0 & 0 & 0 & 0 & 0 & 0 \\
\hline Artemether (5) + haemin (50) & 5 & 3 & 0 & 0 & 1 & 1 & 3 & 2 \\
\hline Artemelher (5) + hatemin (100) & 5 & 4 & 0 & 0 & 2 & 2 & 5 & 4 \\
\hline Artemether $(10)+$ haemin $(50)$ & 8 & 6 & 0 & 0 & 5 & 4 & 8 & 6 \\
\hline Artemether $(10)+$ haemin $(100)$ & 7 & 5 & 0 & 2 & 4 & 3 & 7 & 5 \\
\hline
\end{tabular}

${ }^{a}$ Concentrations of artemether and haemin in $\mu \mathrm{g} / \mathrm{mL}$ are given in parentheses.

$b_{m}=$ Male, $f=$ female.

Table 3. Mortality rates of adult Schistosoma haematobium after exposure in vitro to artemether or haemin, or both substances

\begin{tabular}{|c|c|c|c|c|c|c|c|c|}
\hline \multirow[b]{3}{*}{ Treatment ${ }^{\mathrm{B}}$} & \multirow{2}{*}{\multicolumn{2}{|c|}{$\begin{array}{c}\text { No, of worms } \\
\text { initially }\end{array}$}} & \multicolumn{6}{|c|}{ No. of worms dead after incubation ${ }^{b}$} \\
\hline & & & \multicolumn{2}{|c|}{$24 \mathrm{~h}$} & \multicolumn{2}{|c|}{$48 \mathrm{~h}$} & \multicolumn{2}{|c|}{$72 \mathrm{~h}$} \\
\hline & m & $\mathrm{f}$ & $\mathrm{m}$ & $f$ & $\mathrm{~m}$ & $\mathrm{f}$ & In & f \\
\hline Control (medium only) & 6 & 4 & 0 & 0 & 0 & 0 & 0 & 0 \\
\hline Polyethylene glycol $(1 \cdot 2 \%)$ & 6 & 4 & 0 & 0 & 0 & 0 & 0 & 0 \\
\hline Haemin (50) & 3 & 2 & 0 & 0 & 0 & 0 & 0 & 0 \\
\hline Haemin $(100)$ & 3 & 2 & 0 & 0 & 0 & 0 & 0 & 0 \\
\hline Artemether (10) & 3 & $\overline{2}$ & 0 & 0 & 0 & 0 & 0 & 0 \\
\hline Artemether (20) & 3 & 2 & 0 & 0 & 0 & 0 & 0 & 0 \\
\hline Artemether $(10)+$ haemin $(50)$ & 3 & 2 & 1 & 0 & 3 & 2 & - & - \\
\hline Artemether (10) + haemin (100) & 3 & 2 & 0 & 0 & 3 & 2 & - & - \\
\hline Artemether $(20)+$ haemin $(50)$ & 3 & $\overline{2}$ & 3 & 2 & & & $\ldots-$ & \\
\hline Artemether $(20)+$ haemin $(100)$ & 3 & 2 & 3 & 2 & - & - & - & - \\
\hline
\end{tabular}

${ }^{a}$ Concentrations of artemether and haemin in $\mu \mathrm{g} / \mathrm{mL}$ are given in parentheses.

${ }^{\mathrm{b}} \mathrm{m}=$ Male, $\mathrm{f}=$ female.

With $S$. japonicum and $S$. mansoni worms a further decrease was seen in motor activity after $24-48 \mathrm{~h}$ of incubation and vesicles appeared focally on the tegumental surface. The vesicles were initially small, but became enlarged and eventually collapsed, making the tegumental surface appear rough. Vesiculation reached a peak after $48-72 \mathrm{~h}$. Similar observations were made with $S$. haematobium, but these events occurred approximately $24 \mathrm{~h}$ earlier. After $24-48 \mathrm{~h}$ incubation (with $S$. japonicum and $S$. mansomi) and 18-24 h (with $S$. haematobitm), dilatation of the intestine was usually seen and both male and female schistosomes were stained a reddish yellow-brown colour, which made the worm body cloudy and indistinct. No such staining of the worms was seen in the corresponding control groups.

When adult $S$. japonicum or $S$. mansoni were exposed for $24 \mathrm{~h}$ to $10 \mu \mathrm{g} / \mathrm{mL}$ artemether together with $50 \mu \mathrm{g} / \mathrm{mL}$ haemin, all male and female worms survived. Exposure of $S$. haematobium for $24 \mathrm{~h}$ to the same concentrations of artemether and haemin resulted in the killing of one male worm. All surviving schistosomes showed very feeble movements of the oral sucker. After $48 \mathrm{~h}$ incubation at the same concentrations, all $S$. haematobium and most $S$. mansoni worms had died. Meanwhile, all males of $S$. japonicum had died, whereas all females survived these concentrations. Twenty-four hours later, the remaining $S$. mansoni and $S$. japonicum had also died.
Use of a higher concentration of artemether $(20 \mu \mathrm{g} /$ $\mathrm{mL}$ ) and the same or twice the concentration of haemin resulted in rapid killing of adult $S$. haematobium within $24 \mathrm{~h}$ (Table 3). At any given artemether concentration, more rapid killing of schistosomes was observed at the higher haemin concentration. Finally, exposure of adult $S$. japonicum to an artemether concentration as low as $0.5 \mu \mathrm{g} / \mathrm{mL}$ and the higher concentration of haemin $(100 \mu \mathrm{g} / \mathrm{mL})$ still resulted in effective killing after $72 \mathrm{~h}$ (Table 1).

\section{Discussion}

It is unusual to find a chemical compound which has both antimalarial and antischistosomal properties. Derivatives of artemisinin and the immunosuppressant drug cyclosporin $\mathrm{A}$ are such compounds, and understanding their mechanism of action is of great importance (CIOI.I, 1998). Significant progress has been made with regard to artemether, a methyl ether derivative of artemisinin (MESHNICK et al., 1996; XIAO et al., 2000a), whereas information on the mechanism of antiparasite action of cyclosporin A is still limited (BELL et al., 1996). With regard to artemisinin and malaria, it is believed that 2 sequential steps are involved. Activation of artemisinin inside the malarial parasite by heme or other iron systems results in cleavage of endoperoxide bridges and generation of free radicals, and formation of covalent complexes 
between these free radicals and malaria-specific proteins or specific receptors (MESHNICK et al,, 1991, 1993, 1996; ZHANG et al, 1992; KAMCHONWONGPAISAN \& MESHNICK, 1996; MESHNICK, 1998; DHINGRA et al., 2000 ). Both the parent artemisinin compound and its more active derivative artemether (HIEN \& WHITE, 1993) are rapidly metabolized to the biologically active dihydroartemisinin (WHITE, 1996; VROMAN at al., 1999).

The mechanism of action of artemether on schistosomes is still largely unknown (XIAO et al., 2000a). Our tests in vitro demonstrated that, when schistosomes were exposed to artemether at concentrations of $20 \mu \mathrm{g} / \mathrm{mL}$ or less together with 50 or $100 \mu \mathrm{g} / \mathrm{mL}$ haemin, there was a gradual decrease in worm motor activity, followed by severe tegumental damage, cloudiness of the worm body due to its being stained a deep reddish yellow-brown colour, dilatation of the intestine and, finally, death. Very similar observations were made with all 3 schistosome species studied, but the effect occurred more rapidly with adult $S$. haematobium worms than with adults of $S$. mansoni or $S$. japonicum. Since worms exposed to artemether or haemin alone at the same concentrations exhibited no marked change during the incubation, it seems probable that the interaction of artemether and haemin leads to worm damage.

Schistosomes, like malaria parasites, must ingest host haemoglobin for their nutrition. Schistosomes even contain cathepsins which are similar to malatial cathepsins and which function in the breakdown of host haemoglobin, resulting in pigment formation in the intestines of the worms (KLOETZEI \& LEWERT, 1966). Therefore, it is reasonable to suggest that artemether could also be activated within schistosomes by heme or other iron compounds as it is in malatia parasites, producing toxic compounds and/or free iron radicals, as recently suggested by BUTLER et al. (1998).

Previous studies in vitro showed no effect on schistosomes after exposure to artemether at concentrations as high as $100 \mu \mathrm{g} / \mathrm{mL}$ (XIAO \& CATTO, 1989). It is possible that this was due to the small amount of pigment within the schistosomes' intestines. In a previous study (KLOETZEL \& LEWERT, 1966), the pigment content of one pair of adult $S$. mansoni was estimated to be equivalent to $0.5 \mu \mathrm{g}$ of haemin, which was far less than the amount of haemin added to the medium in our present studies in vitro. On the other hand, schistosomes constantly ingest red blood cells in vivo, and these are relatively rapidly metabolized within the worm intestines with a turn-over rate of once every 3-4 h (LAWRENCE, 1973). Therefore, artemether could interact with the constant pigment formation in the schistosomes' intestines. Female schistosomes produce about 4 times more pigment (KLOETZEL \& LEWERT, 1966), ingest significantly more haemoglobin (ZUSSMAN et al., 1970), and take up red blood cells at a 10-fold higher rate (LAWRENCE, 1973) than male worms, which may explain previous observations that adult females are more susceptible to artemether than male worms (XIAO et al., 2000b and in press).

We conclude that further research is needed to elucidate fully the mechanism of action of artemether on schistosomes, but the present findings, that artemether together with haemin has a harmful effect on schistosomes in vitro, is undoubtedly of relevance, as the use of artemether and other artemisinin derivatives offers new dimensions and potential for schistosomiasis control.

\section{Acknowledgements}

We thank the Kunming Pharmaceutical Corporation for supplying artemether, Dr Eliézer K. N'Goran for providing infected Bulinus trumcatus snails, Mrs Yvette Endriss for help in the laboratory, and Mrs Jennifer $M$. Jenkins for useful suggestions and comments on the manuscript. This investigation received financial support from the UNDP/World Bank/WHO Special Programme for Research and Training in Tropical Diseases (TDR), the Swiss Tropical Institute and the Ninth 5-
Year Key Research Programme of China. J. U. acknowledges support from the Swiss National Science Foundation and the Rudolf Geigy Foundation.

\section{References}

Bell, A., Roberts, H. C. \& Chappell, L. H. (1996). The antiparasite effects of cyclosporin $A$ : possible drug targets and clinical applications. General Phamacologv, 27, 963-971.

Butler, A. R., Gilbert, B. C., Hulme, P., Irvine, L. R, Renton L \& Whitwood, A. C. (1998). EPR evidence for the involvement of free radicals in the iron-catalysed decomposition of qinghaosu (artemisinin) and some derivatives; antimalarial action of some polycyclic endoperoxides. Free Radical Research, 28, $471-476$.

Cioli, D. (1998). Chemotherapy of schistosomiasis: an update. Parasitology Today, 14, 418-422.

Clegg, J. A. (1965). In vitro cultivation of Schistosoma mansoni. Experimental Parasitology, 16, 133-147.

Dhingra, V., Vishweshwar, R. \& Narasu, L. (2000). Current status of artemisinin and its derivatives as antimalarial drugs. Life Sciences, 66, 279-300.

Hien, T. T. \& White, N. J. (1993), Qinghaosu. Lancet, 341, $603-608$.

Kamchonwongpaisan, S. \& Meshnick, S. R. (1996). The mode of action of the antimalarial artemisinin and its derivatives. General Pharmacology, 27, 587-592.

Kloetzel, K. \& Iewert, R. M. (1966). Pigment formation in Schistosuma mansoni infections in the white mouse. American foumal of Tropical Medicine and Hygiene, 15, 28-31.

Lawrence, J. D. (1973). The ingestion of red blood cells by Schistosoma mansoni. Foumal of Parastology, 59, 6063.

Le, W.-J., You, J.-Q., Yang, Y.-Q., Mei, J.-Y., Guo, H.-F., Yang, H.-Z. \& Zhang, C.-W. (1982). [Studies on the efficacy of artemether in experimental schistnsnmiasis.] Acta Pharmaceutica Sinica, 17, 187-193. [In Chinese.]

McIntosh, H. M. \& Olliaro, P. (1999). Artemisinin derivatives for treating severe malaria (Cochrane Review). In: The Cochrane Library, Issue 4. Oxford: Update Software.

Meshnick, S. R. (1998). Artemisinin antimalarials: mechanisms of action and resistance. Médecine Tropicale, 58, supplément 3 , $13-17$.

Meshnick, S. R., Thomas, A., Ranz, A., Xu, C.-M. \& Pan, H.-Z. (1991). Artemisinin (qinghaosu): the role of intracellular hemin in its mechanism of antmalarial action. Molecular and Biochemical Parasitology, 49, 181-189.

Meshnick, S. R, Yang, Y.-Z., Lima, V., Kuypers, F., Kamchonwongpaisan, S. \& Yuthavong, Y. (1993). Iron-dependent free radical generation from the antimalarial agent artemisinin (qinghaosu), Antimicrobial Agents and Chemotherapy, 37, 1108-1114.

Meshnick, S. R., Taylor, T. E. \& Kamchonwongpaisan, S. (1996). Artemisinin and the antimalarial endoperoxidases: from herbal remedy to targeted chemotherapy. Microbiological Reviews, 60, 301-315.

Utzinger, J., N'Goran, E. K., N'Dri, A., Lengeler, C., Xiao, S. H. \& Tanner, M. (2000). Oral artemether for prevention of Schistosoma mansoni infection: randomised controlled trial. Lancet, 355, 1320-1325.

Vroman, J. A., Alvim-Gaston, M. \& Avery, M. A. (1999). Current progress in the chemistry, medicinal chemistry and drug design of artemisinin based antimalarials. Current Pharmaceutical Design, 5, 101-138.

White, N. J. (1996). Malaria. In: Tropical Diseases, Cook G. C. (editor). London: W. B. Saunders, pp. 1087-1164.

Xiao, S. H. \& Catto, B. A. (1989). In vitro and in vivo studies of the effect of artemether on Schistosoma mansoni. Antimicrobial Agents and Chemotherapy, 33, 1557-1562.

Xiao, S. H., You, J. Q., Yang, Y. Q. \& Wang, C. Z. (1995). Experimental studies on oral treatment of schistosomal infection with artemether. Southeast Asian Youmal of Tropical Medicine and Public Health, 26, 306-318.

Xiao, S. H., You, J. Q., Mei, J. Y., Guo, H. F., Jiao, P. Y., Sun, H. L., Yao, M. Y. \& Feng, Z. (1997). Effect of artemether on glucose uptake and glycogen content in Schistosoma marsoni. Acta Pharmacologica Sinica, 18, 363-367.

Xiao, S. H., You, J. Q., Mei, J. Y., Jiao, P. Y. \& Guo, H. F. (1998a). Preventive effect of artemether in rabbirs infected with Schistosoma japonictm cercariae. Acta Pharmacologica Sinica, 19, 63-66.

Xiao, S. H., You, J. Q., Guo, H. F., Jiao, P. Y., Mei, J. Y., Yao, M. Y. \& Feng, Z. (1998b). Effect of artemether on glyceraldehyde-3-phosphate dehydrogenase, phosphoglycerate kinase and pyruvate kinase of Schistosoma japonicum harbored in mice. Acta Pharmacologica Sinica, 19, 279-281.

Xiao, S. H., You, J. Q, Guo, H. F., Jiao, P. Y., Mei, J. Y., Yao, 
M. Y. \& Feng, Z (1998c). Effect of artemether on hexokinase, glucose phosphate isomerase and phosphofructokinase of Schistosoma japonicum harbored in mice. Chinese foumal of Parasitology and Parasitic Diseases, 16, 25-28.

Xiao, S. H., You, J. Q., Guo, H. F., Mei, J. Y., Jiao, P. Y., Yao, $M$. Y., Zhuang, S. N. \& Feng, Z. (1999). Effect of artemether on phosphorylase, lactate dehydrogenase, adenosine triphosphatase and glucose-6-phosphate dehydrogenase of Schistosoma japonicum harbored in mice. Acta Pharmacologica Sinica, $20,750-754$

Xiao, S. H., Booth, M. \& Tanner, M. (2000a). The prophylactic effects of artemether against Schistosoma japonicum. Parasitology Today, 16, 122-126.

Xiao, S. H., Chollet, J., Weiss, N. A., Bergquist, R. N. \& Tanner, M. (2000b). Preventive effect of artemether in experimental animals infected with Schistosoma mansoni. Parasitology Internotional, 49, 19-24.

Xiro, S. H, Utzinger, J., Chollet, J., Endriss, Y., N'Goran, E. K. \& Tanner, M. (2000c). Effect of artemether against Schistosoma haematobium in experimentally infected hamsters. International Fotumal for Parasitology, 30, 1001-1006.

Xiao, S. H., Shen, B. G., Chollet, J., Utzinger, J. \& Tanner, $M$. (in press). Tegumental changes in adult Schistosoma mansoni harbored in mice treated with artemether. Foumal of Parasitology.
Yolles, T, K., Motre, D. V., DeGusti, D. L., Ripsom, C. A. \& Meleney, M. S. (1947). A technique for the perfusion of laboratory animals for the recovery of schistosomes. Foumal of Parasitology, 33, 419-426.

You, J. Q., Guo, H. F., Mei, J. Y., Jiao, P. Y., Feng, J. J., Yao, M. $Y$. \& Xian, S. H. (1994). [Effect of artemether on glycogen, protein, alkaline phosphatase and acid phosphatase of Schistosoma japonicum]. Chinese foumal of Parasitology and Parasitic Discases, 12, 275-278. [In Chinese.]

Zhai, Z. L., Mei, J. Y., Yao, M. Y. \& Xiao, S. H. (1999). [Effect of artemether on nucleoside uptake and nucleic acid content in Schistosoma japonicum]. Chinese foumal of Parasitology and Parasitic Diseases, 17, 231-234. [In Chinese.]

Zhang F., Gosser, D. \& Meshnick, S. R. (1992), Hemincatalysed decomposition of artemisinin (qinghaosu). Biochemical Pharmacology, 43, 1805-1809.

Zussman, R. A. Bauman, P. M. \& Petruska, J. C. (1970). The role of hemoglobin in the nutrition of Schistosoma mansoni. foumal of Parasiology, 56, 75-79.

Received 19 October 1999; revised 19 Fuly 2000; accepted for publication 19 Fuly 2000

\section{Announcements}

\section{Low Priced Publications from Tropical Health Technology}

Students and medical workers from developing countries can purchase medical books and laboratory learning aids from Tropical Health Technology at reduced prices, including:

Manson's Tropical Diseases, 20th edition

Color Atlas of Tropical Medicine and Parasitology, 4 th edition

Lecture Notes on Tropical Medicine, 4th edition.

District Laboratory Practice in Tropical Countries, part 1 (454 pp.) by Monica Cheesbrough is an up-to-date practical bench manual, illustrated in colour and black and white. It includes a parasitology section and also chapters on the staffing, quality management and health and safety of district laboratories, equipment and ordering, clinical chemistry investigations, and the preparation of a training curriculum for district laboratory personnel.

Also available are other up-to-date textbooks covering tropical paediatrics, epidemiology, cardiology, nursing, midwifery, laboratory sciences, and solar energy. Training materials include laminated colour photomicrographs with text covering the microscopical diagnosis of tropical disease.

A publications list with prices (inclusive of postage) and order form can be obtained from Tropical Health Technology, 14 Bevills Close, Doddington, March PE15 OTT, UK; phone +44 (0) 1354 740 825, fax +44 (0) 1354 740013 .

\section{African Index Medicus (AM) Programme \\ An International Index to African Health Literature and Information Sources}

In order to give access to information published in or related to Africa and to encourage local publishing, the Association for Health Information and Libraries in Africa (AHILA), with the technical support of the World Health Organization, initiated a programme to create an international index to health literature generated in African countries: the Africun Index Medicus.

The creation of the regional index is a collaborative and participatory process. Firstly, African countries create national health databases using a common methodology. Local information services and products are provided for national health professionals. National production should ensure self-sufficiency and sustainability at country level and the tailoring of services according to local needs.

The various national databases are then merged into a regional database to which are added bibliographic records relating to health in Africa from other international existing sources such as WHO's WHOLIS, MEDLINE, POPLINE etc. to produce the African Index Medicus in printed or electronic form, eventually CD-ROM. It is distributed to African countries as part of an affiliated membership to AHILA for institutions outside the region.

At this stage, AHILA, with support from WHO, is looking for further sponsoring partners at bilateral level with African countries not yet participating in the Project. Sponsorship comprises equipment and training of stafff and could be part of an information component of a health related project in the country, which may also include use of communications and CD-ROM.

Further information can be obtained from Mrs Lucilda Hunter, The Library and Documentation Centre, WHO Regional Office for Africa, P.O. Box BF 773, Belvedere, Harare, Zimbabwe. 